or so he had again become restless, with rapid pulse and respirations, and the pallor had increased. After another intravenous injection of saline solution and adrenalin the patient was chloroformed. The skin and muscles wound was opened up and the kidney was exposed. On opening the muscles a quantity of blood with a large amount of clot escaped and the kidney was then seen to be bleeding freely from the incision in the cortex. So the pedicle of the kidney was separated freely, transfixed, and ligatured with silk and the kidney removed. The remaining cavity was cleared as quickly as possible of blood clot and the wound was closed, a drainage-tube and gauze packing being inserted.

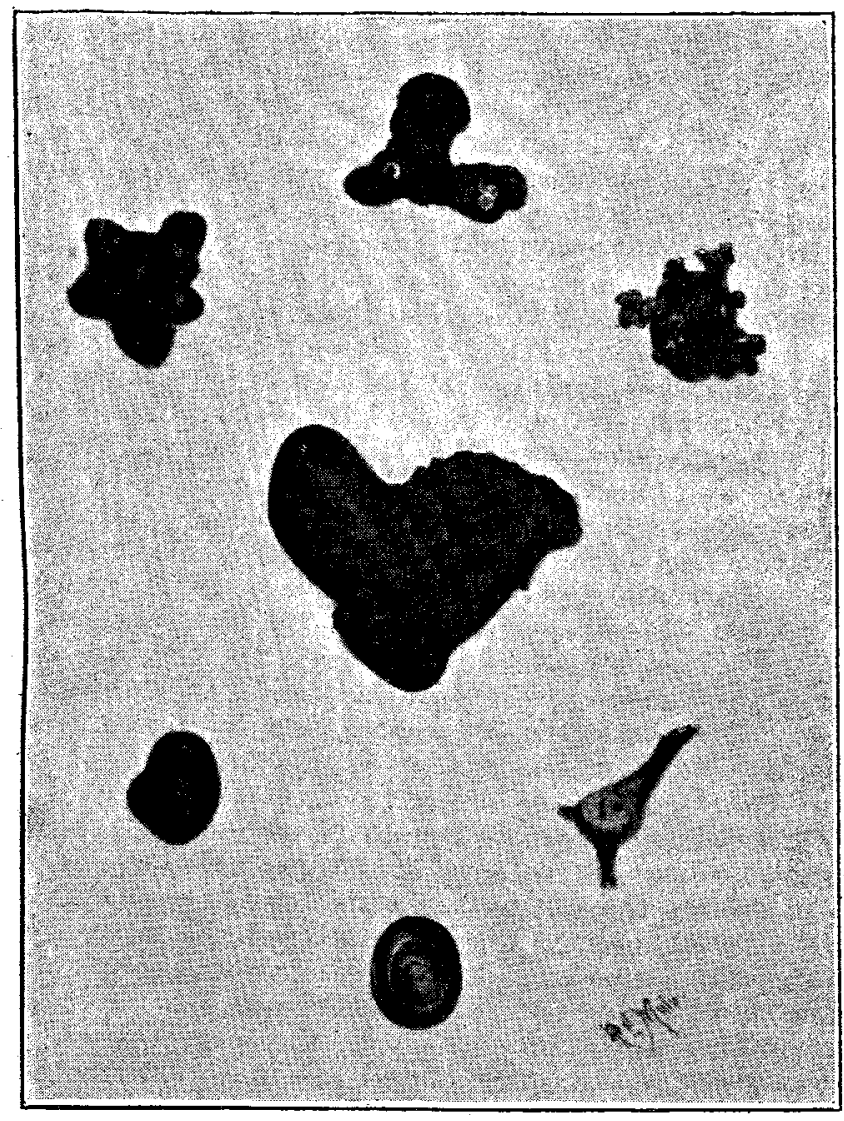

Oxalate of lime calculi from kidney.

The patient stood the operation very well. His pulse became stronger and rather slower and there was no restlessness. Saline solution and adrenalin subcutaneously and then saline solution per rectum were given later. For the next day or two the patient complained of great thirst but otherwise was very well. Blood and clots were passed per urethram for about eight days afterwards, then the urine remained smoky in colour for about a fortnight. On the third and fourth days after operation the temperature was $100^{\circ}$ and $101.6^{\circ} \mathrm{F}$., but remained normal during all the rest of his illness.

For seven days before operation the daily quantity of urine passed averaged 35 ounces; for four days after operation, not including the day of operation, the daily quantity averaged 69 ounces; while for the next seven days it averaged 40 ounces, so that neglecting the increased flow of fluid for the first four days after operation the quantity of urine secreted before and after operation remained much the same; presumably the right kidney had not discharged its function much for a long time previously.

The wound drained for some time and then slowly healed. The patient was discharged from hospital in five weeks in a very satisfactory condition. Examination of the urine a fortnight after operation showed no calcium oxalate crystals or blood corpuscles.

Pathology.-Examination of the excised kidney showed it to be rather larger than normal and to contain at its lower end a thin-walled cyst of about the size of a walnut. The cortex was thinned all over but more markedly at some places. The pelvis and calyces were dilated, and imbedded in the calyces were found four more calculi, each of about the size of a pea, one smooth, two very rough and irregular, with sharp spinous processes, and one of an elongated pear shape, with bulging head. They were all very hard and black in colour and were found, along with those removed at the first operation, to consist of calcium oxalate.

Microscopic examination of the excised kidney showed no evidence of pyelonephritis. The medullary layer was greatly atrophied, due to the dilated condition of the calyces. Small hæmorrhages from distended vena recta were seen in this layer. There was an increase of the connective tissue between the vessels and tubules, a secondary interstitial change, following the atrophy which was of some duration. The secreting tubules in the cortex showed cloudy swelling of their epithelial lining; otherwise they were quite normal.

Remarks. - It is impossible to detect some calculi without an exploratory incision of the kidney, and it is equally difficult to discover all stones even when the kidney lies in the hand with an incision made along the convex border and the finger searching the pelvis. In this manner three stones were discovered in the case now recorded, but four others were only seen when the kidney was completely split up after removal.

The points to which attention is directed are the following : 1. That deep catgut sutures along the incised border of the kidney failed to check hæmorrhage when the kidney was allowed to drop back within the abdomen. 2. That when the hæmorrhage could not be arrested removal of the kidney saved the case. 3 . That the reactionary hæmorrhage was a fortunate occurrence, seeing that the kidney was far from healthy owing to hydronephrosis, cysts, and other changes, also owing to the concealment of four more stones in the solid parts of the organ, so that the operation would have been only partially successful had the nephrectomy not been undertaken. 4. Oxalate of lime calculi are more frequently single. 5. That there was no history of renal colic with rigors, nausea, vomiting, and perspirations. 6. That the shadow of the calculi was seen distinctly on the fluorescent screen. Phosphatic calculi are said to give a very dark shadow, while calcium oxalate calculi give a much lighter shadow and those of uric acid are seen only with difficulty. * The seven calculi weighed 104 grains; the large one 55 grains.

\section{NOTE ON A CASE OF VESICAL CALCULUS, THE NUCLEUS OF WHICH WAS A REVOLVER BULLET.}

By C. F. LASSALLE, M.D., C.M. EDIN., D.P.H. OxON., SENIOR ASSISTANT SURGEON, COLONIAT HOSPITAL, PORT OF SPAIN, TRINIDAD, BRITISH WEST INDIES.

Trre subject of this note is, I think, of sufficient interest to deserve publication.

The patient, an East Indian boy, then seven years of age, was accidentally wounded in the right hip by a revolver bullet on Oct. 12th, 1902. There was no wound of exit. He was taken to the nearest district hospital where the medical officer detained him under treatment for 14 days. He was then discharged with the wound of entrance almost healed. This wound soon healed completely. The boy was next treated for urinary trouble-viz., incontinence of urine-at the Colonial Hospital, Port of Spain, from August 31st to Sept. 6th, 1906. The history of the bullet wound was obtained, but the existing condition was ascribed to an elongated and somewhat tight foreskin, the removal of which certainly afforded temporary relief of the bladder symptoms. The bladder was not explored. $\mathrm{X}$ ray examination revealed nothing definite. His symptoms returned soon after he left hospital and he suffered from incontinence of urine as well as intense pain whenever he attempted to pass urine. His condition never improved, in spite of various lines of treatment which his anxious father had recourse to, and his sufferings had increased considerably when he was admitted to the San Fernando Hospital on Dec. 13th, 1907.

On admission the patient was a thin, delicately built boy aged 12 years, with a very anxious, perturbed countenance. He frequently and with tears in his eyes would cry out imploringly, "Doctor, it hurts me too much ; do take out the bullet." His temperature was $99.4 \circ \mathrm{F}$. The heart and lungs were normal. In the hypogastric and lower part of the nmbilical regions the distended bladder was palpable. On the right side and below the umbilicus there was an 
extremely tender and indurated area. On the introduction of a sound into the bladder a vesical calculus was distinctly made out.

On Dec. 18th the patient was put under chloroform and the calculus was removed by suprapubic lithotomy. This was attended with difficulty owing to the size of the calculus. The bladder was drained through a perineal opening, as the calibre of the urethra was not large enough to admit of the passage of a sufficiently large catheter to insure free drainage and passage of any fragments which might have been left behind. The calculus weighed 520 grains and measured 13. inches in length and $4 \frac{1}{4}$ inches in circumference at the widest part. Section with a fret saw showed the two halves

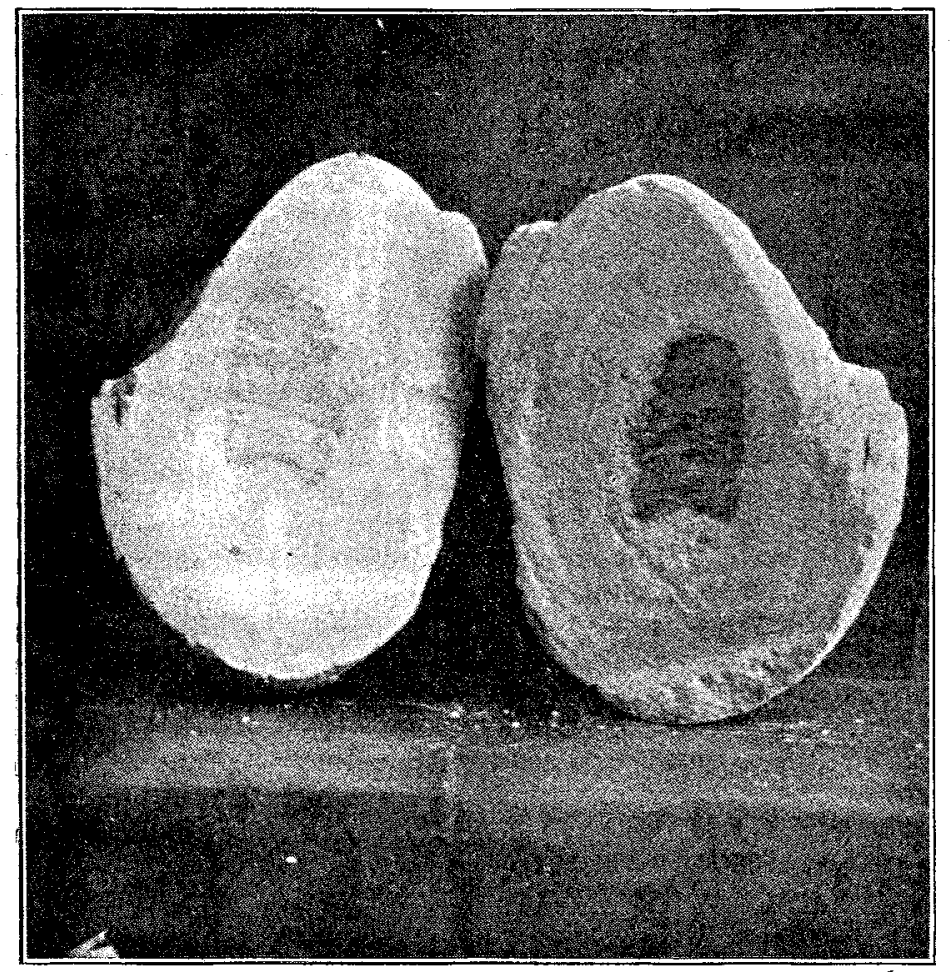

The illustration shows the stone its exact size.

of a revolver bullet imbedded in the two segments of the calculus - the revolver bullet being the nucleus. Chemical analysis showed the calculus to be chiefly phosphate of calcium with a trace of oxalate of calcium.

The patient made a fair recovery considering a certain amount of laceration of the bladder wall which was un avoidable. There was some suppuration around the abdominal wound. He was discharged from hospital cured on Feb. 17th, 1908. I have seen him several times since. He is in good health, his urinary functions being normal.

Trinidad.

\section{THE TREATMENT OF SPINA BIFIDA BY DRATNAGE OF THE CEREBRAL SUBDURAL SPACE.}

BY PETER PATFRSON, M.B., C.M. GLASG., M.R.C.S. ENG. L.R.C.P. LOND,

SURGCON TO THE GLASGOW ROYAL INFIRMARY.

MANY cases of spina bifida can be treated by simple $\epsilon \mathbf{x}$ cision of the sac and suturing the soft structures over the cord, but where the deformity is of the meningo-myelocele variety there is considerable danger in producing injury to the cord and nerres when dissecting these from the adherent sac, and yet if the tissues covering the cord are thin and about to rupture an operation of some kind must be done if the patient's life is to be saved.

It has been recommended in such cases to separate the strip of skin to which the cord is adherent from the remainder of the sac, cut away the redundant tissue, replace the cord with its attached strip of skin in the defective canal, and then close the wound by bringing together the superficial soft tissues. It seems to me that in this operation there is an element of danger in placing in the canal tissue, which is difficult to render aseptic and which, even if sterile, may continue its normal cutaneous function in its new situation. Injections of Morton's fluid or similar solutions are also not free from risk, as we have no means of limiting their sphere of action unless by posture, and cases of sudden death after their use are by no means unknown.

An infant, two months old, was brought to me for the relief of a meningo-myelocele on which I operated and removed the sac, but as the result was unsatisfactory I decided to trephine the skull and to drain the subdural space into the soft tissues of the scalp. The spina bifida was congenital and was associated with a double talipes equino-varus and paresis of the legs. There was also a slight degree of hydrocephalus. The defect in the spine involved the eleventh and twelfth dorsal and first Iumbar vertebræ. For the first six weeks of the child's life the swelling had remained small, but it then increased rapidly till it reached the size of an adult fist. The skin was thin, red, and very tense, and seemed almost on the point of rupture. By transillumination the cord could be seen running along the posterior part of the sac with the nerves crossing it to reach their point of exit. To diminish the immediate danger, that of rupture, the sac was punctured and four ounces of fluid were withdrawn, but by the following day the swelling had almost regained its original size. The sac was now laid open by an incision so placed as to avoid the cord and nerves. These were found to be firmly adherent to the sac and could be dissected off only with difficulty. The spinal canal was found to be represented by a very shallow groove, on each side of which the ends of the defective arches could be felt as three hard knobs. The whole of the skin down to the base of the swelling was removed; the cord was laid in the spinal groove and covered by sliding and suturing healthy tissues over it. After this operation the tumour slowly enlarged till, owing to the stretching of the cicatrix, cerebro-spinal fluid commenced to escape through the stitch wounds. It was now decided to relieve the tension by draining the cerebral subdural space into the subcutaneous tissues of the scalp. This was done by removing a disc of bone from the right parietal in front of the motor area, opening the dura mater by a crucial incision, and turning the flaps thus formed over the edge of the opening and stitching them to the pericranium. The superficial wound was then closed and a collodion dressing was applied. For several days after this operation the scalp surrounding the wound was very odematous, the odema extending to the upper eyelid of the same side, and then it gradually disappeared. The spina bifida meanwhile steadily diminished in size till palpation failed to show the presence of fluid in its interior, the skin at the same time becoming normal in colour and firm in texture. The patient remained well, so far as the spina bifida was concerned, for two months, when the hydrocephalic condition became more pronounced. During these two months the defective laminæ had grown considerably, so that the gap over the cord was reduced to about half an inch.

Operation for permanent drainage of the ventricles was now performed by removing a disc of bone from the left parietal in front of the motor area and opening and stitching the dura mater as in the previous operation. Six silk threads were then formed into a bundle by lightly tying them together at one end, the other end being left loose. The tied end of this bundle was pushed through the cerebral substance, with the aid of sinus forceps, till the escape of cerebro-spinal fluid showed that the ventricle had been reached. The forceps being withdrawn the threads were introduced another quarter of an inch into the cavity of the ventricle, so that if the cerebral substance should become thickened from collapse of the distended ventricles drainage might still be maintained. The loose outer ends of the threads having been cut short, so as to leave an inch projecting from the surface of the brain, were then spread out radially into the superficial tissues of the scalp. The skin was closely stitched and a collodion dressing was applied. On the following day the scalp was markedly odematous and this gradually increased till four days later the left eye was completely closed. By the tenth day the œdema had disappeared, except for a slight puffiness in the neighbourhood of the trephine opening. As a result of this operation the head diminished in size, the fontanelles became lax, and the parietals overlapped along the line of the interparietal 